\title{
A configuração das alianças golpistas nas ditaduras de Brasil e Argentina: uma perspectiva a partir da imbricação cívico-militar*
}

\author{
The configuration of putschists alliances in \\ dictatorships of Brazil and Argentina: a perspective \\ from the imbrication civil-military
}

Hernán Ramírez**

Resumo: Neste artigo nos propomos a debater a configuração das alianças entre setores civis e militares que deflagraram os golpes de Estado e instauraram regimes ditatoriais no Brasil e na Argentina. Interessa-nos caracterizar tanto a sua constituição inicial quanto as dinâmicas que produziram sucessivas configurações dentro dessas próprias administrações, determinando nuances particulares, já que elas incidiram profundamente tanto nas políticas implementadas quanto nos setores que se lhes podiam contrapor.

Palavras-chave: Ditaduras do Cone Sul, Alianças golpistas, Cívico-militar

Abstract: In this article we propose to discuss the configuration of alliances between civilian and military sectors that sparked coups d'etat and established dictatorships in Brazil and Argentina. Interest to characterize both their initial establishment and the dynamics that produced successive administrations within those settings, determining particular nuances, as they focus on policies that deeply if implemented as sectors that could counter it.

Keywords: Southern Cone dictatorships, Putschists alliances, Civil-military

\footnotetext{
* Artigo elaborado a partir de um projeto financiado pelo CNPq.

** Professor da Universidade do Vale do Rio dos Sinos (UNISINOS). Doutor em História pela Universidade Federal do Rio Grande do Sul (UFRGS) com Pós-doutorado no Instituto de Pesquisas do Estado do Rio de Janeiro (IUPERJ). E-mail: <hramirez1967@yahoo.com>.
} 
Os golpes de Estado que ocorreram nos países do Cone Sul não foram eventos exclusivamente militares, a participação civil foi fundamental, seja no processo de deslegitimação dos governos democraticamente constituídos, seja na sua interrupção por vias de fato e na constituição e legitimação dos governos autoritários. Lado a lado com militares, destacam-se especialmente as presenças de segmentos empresariais, latifundiários, rentistas urbanos, tecnocratas, membros da Igreja Católica, bem como, em papel subordinado, profissionais liberais e até donas de casa.

Não obstante, as conjunturas desempenharem papel importante, governos que se estenderam por mais de vinte anos no Brasil, dezessete no Chile, doze no Uruguai e mais de sete em cada uma das duas últimas ditaduras argentinas, separadas por um breve interregno democrático de pouco mais de três anos, responderam a forças estruturais e não apenas à mera circunstância. As ditaduras foram consequências de toda uma história anterior e suas sequelas se arrastariam por décadas, marcando diferentes momentos determinados pela configuração de alianças entre distintos atores sociais, submetidas a dinâmicas que podiam aprofundar esses laços ou, pelo contrário, levar a enfrentamentos entre seus membros, abrindo brechas entre eles.

\section{As alianças golpistas}

Essa participação civil pode ser observada na origem de diversas autoridades do alto escalão governamental. No caso uruguaio, civis foram presidentes da república, exceto o último; no caso brasileiro, os vice-presidentes e a maioria dos membros do Parlamento também o eram, instituição esta que continuou funcionando com pequenas interrupções; assim como em todos os casos nacionais, indivíduos que não vestiam uniformes integraram a maioria dos quadros dos ministérios, da justiça, do serviço diplomático, dos governos estaduais e municipais, e de outras instituições estatais.

Evidentemente, o domínio militar se manifestou em diversos graus, sendo o caso argentino o mais acentuado. Não obstante, esse predomínio não deve ser interpretado de forma errônea como sinal de força, pois ele bem poderia ser o contrário, já que os agentes que o constituíram foram incapazes de instaurar um domínio mais consensual, devendo fazê-lo mediante o emprego da repressão e do medo em muito maior medida, em especial se comparado com o caso brasileiro.

Tal asseveração não implica em entrar na falsa discussão acerca da brandura ou dureza das ditaduras, apenas marca o ponto ao qual, por 
distintas necessidades, elas chegaram a ocorrer, sem se poder determinar, numa hipótese contra-factual, seu comportamento caso mudassem as condições sobre as quais atuavam.

Igualmente, nossa perspectiva não se restringe apenas às circunstâncias dos golpes de Estado, ela abarca um longo processo, que remonta aos momentos prévios e se estende além do período ditatorial. As rupturas institucionais foram processadas quando os sistemas democráticos estavam vigentes, sem que as forças que nele atuavam fossem capazes de debelá-los. É, nesse momento que as alianças cívicomilitares se constituem e começam a atuar, deslegitimando os governos constituídos, estratégia que era parte do jogo político, não podendo ser vista apenas como um preparativo para as quebras constitucionais.

Diversos setores da sociedade civil estiveram na primeira fila durante os golpes de Estado e nos governos autoritários que se constituíram a posteriori, seja apoiando-os ou deles participando diretamente, algumas vezes de forma mais aberta, em outras encobertas. E, se bem que não fossem as armas principais, sua articulação por trás dos bastidores foi central em muitos casos, motivo pelo qual se torna relevante conhecer sua forma de agir.

A imbricação profunda de diversos interesses, não necessariamente convergentes na sua totalidade, por um período de tempo prolongado não é uma invenção autoritária, mas subjacente à constituição de diversos sistemas sócio-político-econômicos. De fato, o populismo, contra o qual lutavam as forças que constituiriam esses governos ditatoriais, igualmente foi fruto disso. Firmado sobre um tripé composto por burocratas estatais, incluindo militares, membros da burguesia nacional e do movimento operário sindicalizado.

Nos casos por nós analisados, também percebemos uma tríade sustentação às ditaduras no poder, referindo-nos concretamente a militares, empresários e tecnocratas orgânicos, cujos pesos e características foram se alterando com o tempo assim como foram incorporados outros atores sociais, de acordo com as exigências que lhe demandavam as circunstâncias, referindo-nos especialmente à parte da hierarquia católica.

Uma hipótese desse tipo não representa uma novidade, interpretações nesse sentido têm sido correntes nas ciências sociais. Para nos remeter apenas a alguns exemplos clássicos, Guillermo O'Donnell formulou essa tese para o caso argentino, na década de 1970, a qual culminaria na sua proposição sobre o Estado burocrático autoritário, na década seguinte (1977 e 1982); René Armand Dreiffus (1981) discutiu essa intrincada 
trama para o caso do Brasil; e, mais recentemente, baseando-se em Samuel P. Huntington (1992), Ricardo Sidicaro fez uma meticulosa análise teórica e empírica acerca das alianças que se construíram em torno das ditaduras argentinas instauradas a partir dá década de 1930 (2004).

Estudos desse tipo marcam um caminho claro, mas complicado de transitar, já que sua dinâmica é complexa. Quando nos remetemos a categorias muito extensas, como militares, empresários, latifundiários, rentistas, tecnocratas, profissionais e religiosos, sem adjetivos, corremos o risco de englobar indivíduos que possuem características diferentes, que os podem levar, inclusive, a duros enfrentamentos com seus próprios pares. Refregas que podiam exceder, e de fato o fizeram, os âmbitos que habitualmente associamos a esses personagens. Longe de serem homogêneas, tais categorias estão sulcadas por marcadas clivagens internas, com comportamentos muito diferentes entre si, incluindo os associativos e de atuação política.

Paralelamente a estabelecer alianças com aqueles segmentos que possuíam interesses afins, por caráter transitivo também passariam a hostilizar os que se aliavam com suas facções rivais, que se convertiam assim em seus inimigos, estabelecendo dessa forma uma sorte de relacionamentos cruzados. A luta política era uma batalha entre alianças de frações, que podiam incluir segmentos de atores aparentemente similares, motivo pelo qual sintetizaremos, na continuação, essa dinâmica.

De modo histórico mais concreto e em grandes rasgos, podemos resumir que o empresariado brasileiro, que atuava nos anos 1960, adotou suas feições muito antes, basicamente durante o varguismo, regime que, se bem tenha imposto uma organização de caráter corporativa de modo geral, teve com esse segmento social um trato diferenciado, devido a que seu poder de inversão lhe conferia maior autonomia em relação a outros agentes, situação que se expressa basicamente no fato ter se estabelecido um sistema dual de representação, com instituições para se relacionar com o Estado e outras entre os próprios empresários. ${ }^{1}$

A regionalização foi outra de suas características sobressalentes de representação empresarial, com predomínio paulista, mas contando com organizações de peso em outros espaços, particularmente no Rio de Janeiro, em Minas Gerais e no Rio Grande do Sul, o que enfraquecia

1 Existe uma profusa bibliografia a respeito, uma excelente síntese, tanto para o caso brasileiro como para o argentino, em Anibal Jáuregui (2002 y 2004). 
as entidades de caráter nacional e ainda mais as da burguesia como um todo.

Por sua vez, as corporações do segmento empresarial argentino tiveram suas raízes no século XIX, quando foram criadas duas das suas entidades mais relevantes: a Sociedad Rural Argentina (SRA) e a Unión Industrial Argentina (UIA). Tal situação seguia as características constitutivas do sistema político, manifestas num centralismo acentuado que dava primazia às organizações portenhas, que de fato atuavam como nacionais; uma fraca distinção por fração de capital, marca constitutiva do capital argentino, e prioridade dada à interlocução com as organizações da grande burguesia, cujos componentes, em geral, tinham origem remota e aristocrática, por herança ou arribo.

$\mathrm{Na}$ década de 1940, essa matriz entraria em conflito com a emergência do peronismo, que primou por alianças com o capital menos concentrado e de gênese mais recente, originando assim um ferrenho conflito em nível corporativo, basicamente entre a UIA e a Confederación General Económica (CGE), criada com esse propósito. Tal rivalidade não se plasmou do mesmo modo no setor agropecuário, nesse caso teve lugar mais no plano discursivo e em algumas medidas econômicas concretas que o prejudicaram, em especial aos grandes comerciantes de grãos, transferindo recursos para outros setores através da ação estatal, mas não foi fundada nenhuma organização que fizesse frente à poderosa SRA.

Isto leva a observar que o conflito social nesses dois países passava mais pelo Estado do que por uma luta direta, tanto em níveis inter quanto intra classe, tal como sugerem Jorge Schvarzer e Ricardo Sidicaro (1987). Tal fenômeno conduzia a uma sobrepolitização do social, como observou Juan Carlos Portantiero (1987), já que, para se posicionar melhor perante seus potenciais concorrentes, os atores se inclinavam a estabelecer relações fluídas com o Estado ou buscavam controlá-lo de múltiplas maneiras. De todos os modos, consideramos que tal característica não seria apenas uma deformação local, já que o crescimento do peso estatal é uma constante no capitalismo, o que leva a comportamentos mediados dessa forma, inclusive com canais institucionalizados para isso, como o lobby, conceito com o qual muitas vezes erroneamente se subsumem outros tipos de ações. A magnitude desse fenômeno foi tal que Philippe Schmitter chegou a qualificar o século XX como o século do corporativismo (1992).

A partir da década de 1960 pode se observar uma transformação radical no processo de formulação política, não apenas nos casos 
analisados, mas em sentido mais amplo. No capitalismo ocidental a classe dominante, si se nos permite a redundância, domina a distância, são outros os que administram o poder de forma cotidiana, sobre os quais se devem exercer diferentes mecanismos de controle para que não se tornem independentes. Só em casos excepcionais, e sustentamos que os golpes de Estado são exemplos deles, o controle é exercido de forma mais direta. Em geral, é a burocracia que se ocupa de desempenhá-lo, para o que é recrutada e formada de acordo com determinado tipo de demandas e propósitos. Não obstante, sabemos que ela não é totalmente fiel, podendo ter seus próprios interesses, organizar-se e lutar por eles.

Por isso, na hora de analisar a participação da burocracia nesta aliança devemos realizar algumas considerações prévias, tanto de suas características constitutivas quanto das transformações pelas quais atravessou durante esse período, seja na ordem local ou internacional.

Não obstante existirem poucos estudos comparativos a respeito, o trabalho clássico de Kathryn Sikkink (1993) nos mostra que a burocracia brasileira era recrutada na sua maioria por mecanismos meritocráticos, era mais vasta e gozava de melhores salários, outros tipos de vantagens e uma consideração social que não dispunha sua similar argentina. Isto não marcava apenas uma diferencia no ethos burocrático, tinha reflexos também em vários aspectos, em especial na forma como seus membros se colocavam dentro dos aparelhos de Estado e perante outros setores da sociedade civil.

Por outro lado, representando uma tendência mundial (Dezalay; Garth, 2002) a gerência das políticas públicas, e em particular das áreas econômica e conexas, passou a demandar um alto grau de complexidade para o qual o político tradicional não estava, nem está, preparado, requerendo o auxílio de expertos, com trânsito na esfera privada, cujo o número tem crescido ainda mais devido à superespecialização que se impôs, muitas vezes como estratégia da própria burocracia internacional, que dessa forma se converteu na única habilitada para esse propósito, já que apenas ela domina os códigos dessa nova arte, excluindo artificial e expressamente aos não iniciados, afastando até, não raras vezes, os próprios políticos e burocratas tradicionais.

Além disso, essa nova realidade tem criado vários problemas na forma como as políticas públicas se processam, não apenas dentro do próprio Estado, mas fundamentalmente entre os atores sociais que com elas se beneficiam ou prejudicam. Esse tipo de conhecimento é escasso e caro, também demanda profissionais de tempo integral para que o conheçam, produzam e o apliquem. Motivo pelo qual os empresários, 
os políticos tradicionais, assim como o grosso da população, já não dispõem das condições mínimas para seguir essa carreira, devendo delegá-la a outros agentes, com os quais estabelecem alianças, algumas vezes de subordinação, mas nem sempre.

Nesse novo cenário tampouco os indivíduos isolados são suficientes, embora talvez sejam necessários líderes para comandar os processos, agora a força se instala nas equipes que possam cobrir as extensas áreas de atuação pelas quais se espraiam e a enorme quantidade de cargos que têm de ocupar. Nem sequer os militares conseguiram escapar a essa nova lógica, pois precisaram delegar o controle de muitas áreas, em especial a econômica, a esse novo tipo de profissionais, inclusive vários sucumbiram politicamente em embates contra esses agentes, como foi o caso do general argentino Ramón Genaro Díaz Bessone, que perdeu a batalha para a equipe do ministro da Economia, José Alfredo Martinez de Hoz (h).

Em relação ao segmento militar, apenas para os efeitos do que aqui nos ocupamos, observamos que algumas características peculiares das Forças Armadas no seu conjunto, sues ramos e grupos, sejam estes formais ou informais, os levaram a diferentes concepções, modos de atuar e de se relacionar entre eles e com outros segmentos da sociedade civil.

Assim, podemos fazer uma releitura das clássicas distinções entre as linhas militares de cada país. No caso brasileiro a mais importante delas era a que se dava entre a "linha-dura" e a "Sorbonne", ou "esguianos", como eram chamados estes últimos, com reflexos na forma como viam, e no seu momento atuaram, na economia, junto aos empresários e por seu lugar na dinâmica social em sentido amplo².

O grupo da "Sorbonne" recebeu esse apelido por nuclear militares que se consideravam mais intelectualizados, por terem frequentado a Escola Superior de Guerra (ESG), os quais, na conjuntura do golpe, ocupavam cargos na estrutura burocrática do Estado, a partir dos quais se aproximaram de posições desenvolvimentistas; já os da "linhadura" eram geracionalmente mais velhos, portanto, hierarquicamente superiores, não tinham pertencido a essa Escola, sustentavam posições ideológicas mais conservadoras e se encontravam à frente das tropas no momento do golpe.

As clivagens entre ambas as linhas tinham sido introduzidas com a criação da ESG, em 1949, data que a separa em quase em meio século

2 Sobre as divisões na arena militar, ver o trabalho clássico de João Roberto Martins Filho (1995). 
em relação de sua similar argentina, fundada em 1900. Isto não marca apenas uma distancia temporal, essas duas instituições surgiram em momentos diferentes, tanto local quanto internacional, o que deixou suas marcas nas estruturas e modos de atuar das próprias Forças Armadas, já que, ao fim e ao cabo, representavam o estágio mais elevado na sua socialização.

Referente ao objetivo central deste artigo, a mais importante diferença era a admissão de civis entre as fileiras da Escola brasileira, possibilidade que atraía para suas salas de aula a líderes empresariais e altos quadros da burocracia que, desse modo, podiam aproveitar o ambiente de confraternização para estender pontes com os militares, contatos que podiam se somar a outros, estabelecidos fora desse âmbito, rompendo assim, em parte, o isolamento corrente nesse tipo de instituição. Essa relação com segmentos da sociedade civil era posteriormente prolongada mediante a ação da Associação dos Diplomados da Escola Superior de Guerra (ADESG), que teve vários empresários como seus presidentes, promovendo também outros cursos e a atuação de civis, como conferencistas, entre suas atividades mais relevantes.

No caso argentino, o ingresso de civis na Escuela Superior de Guerra só foi possível em 1986, durante os primeiros anos da redemocratização. Isso não implica que não existissem nexos, mas que eles se estabeleciam por outros canais, mais informais, muitas vezes familiares, que aproximavam o setor castrense das vicissitudes do mundo fora da caserna.

Essa diferença era suprida em parte pelo fato de que o Exército argentino usufruía de maior prestígio que seu par brasileiro, atraindo membros das elites para suas fileiras ou para efetuar uma espartana socialização nas suas academias.

Assim, no caso da Argentina, as diferenças entre os distintos grupos militares passavam por outras vias e remontavam em essência à oposição que fizeram ao governo peronista. Várias foram as categorias empregadas para denominar as duas correntes antagônicas principais, as quais podem ser sintetizar na oposição entre azuis, liberais, legalistas ou politicistas contra colorados, nacionalistas, corporativistas ou duros.

Os agrupamentos surgidos em torno de cores faziam referência à forma como os militares são divididos nas simulações de guerra e antigamente tinham distinguido a unitários e federales. Concretamente, e de forma geral, os azuis eram de tendências mais liberais, com certo diálogo com as forças políticas, mais favoráveis a soluções democráticas e a devolver rapidamente o poder às mãos civis, quando o ocupavam 
por meio de golpes de Estado; já os colorados eram de tendências conservadoras, corporativistas e nacionalistas, sendo propensos a permanecer por mais tempo no poder, com o objetivo de reformular as bases estruturais antes de devolvê-lo.

Outro dos âmbitos privilegiados para que civis e militares estabelecessem relações era o complexo industrial militar. O varguismo e o peronismo promoveram o desenvolvimento de várias empresas estatais, mas tal processo reconhece traços mais longínquos, colocando esses segmentos num tramado em que confluíam múltiplos interesses, particularmente militares, empresariais e burocráticos, que os aproximavam em torno dos problemas reais da economia e, porque não dizer, dos benefícios legais, ou nem tanto, que recebiam.

Desse modo, podemos estabelecer pontos de contato com a distinção que Paula Canelo (2004) estabeleceu para o caso argentino entre "senhores da guerra" e burocratas, ou seja, entre aqueles militares que faziam carreira no comando de tropa e os que o faziam dentro das estruturas de outros aparelhos estatais. No caso brasileiro, a "linha-dura" se aproximava muito à primeira categoria do caso argentino enquanto que a "Sorbonne", em parte, à segunda.

Assim, comprovamos que existiu um entrelaçamento distinto nos casos nacionais: no Brasil, os empresários e tecnocratas que tiveram maior participação no golpe e no governo autoritário posterior estenderam relações mais estreitas com os militares do grupo da "Sorbonne", ou seja, opostos aos "senhores da guerra" representados pela "linha-dura", que tiveram maior peso durante a primeira etapa do regime autoritário. Na Argentina, parte dos "senhores da guerra" foi quem fez aliança com a alta burguesia, à qual estavam unidos por laços familiares e com a qual compartilhavam o apreço pelo liberalismo econômico; os burocratas pretenderam imprimir um sentido nacionalista, mas pouco a pouco foram relegados e só mais tardiamente se aproximaram de segmentos marginais do empresariado e alguns grupos tecnocráticos de menor relevo naquele momento, como os aglutinados em torno da Fundación Mediterránea (FM), que na época ainda não estava identificada com o neoliberalismo.

Por fim, a aliança entre a espada e o dinheiro se completaria com a cruz, reeditando um clássico tripé do capitalismo ocidental. Há tempos que as forças conservadoras eram profundamente católicas, circunstância que se potencializaria ao se aguçar a luta anticomunista nestas latitudes, sendo a alta hierarquia eclesiástica peça-chave nas forças que atuavam em prol da ordem, aportando seu prestígio, estruturas e discurso. Tal 
imbricação é mais do que visível no Instituto de Pesquisas Econômicas e Sociais (IPÊS), que usou da roupagem católica para promover muitas das suas atividades. Por exemplo, imprimiu milhões de comentários das encíclicas Mater et Magistra e Pax in Terris, distribuídos por periódicos comerciais; serviu-se de vários padres para penetrar em setores profissionais, das donas de casa e outros refratários aos empresários ou tecnocratas desse cunho, como os movimentos estudantil, operário e comunitário; e utilizou fartamente parte da sua ampla estrutura, particularmente universidades, gráficas, arquivos e outros tipos de locais, ajuda com a qual obtiveram parte importante do embasamento para uma atuação de massa.

\section{Os golpes de Estado como processo}

As quebras institucionais têm data e hora marcada, mas os processos que as engendram são de origem difusa, muitas vezes imbricados profundamente com a matriz política dos países, motivo pelo qual a sua compreensão deve levar em consideração essa perspectiva de longo prazo, que nos ajuda a avaliar melhor as forças que estão em jogo. Um exemplo disso é o caso brasileiro, no qual o general Olympio Mourão Filho se apressou em deflagrar o golpe, mas não conseguiu capitalizar o fato, passando o poder às mãos de outros grupos golpistas que operavam paralelamente.

Essa disjuntiva entre o real e o aparente também tem que ser transladada à ponderação de certas circunstâncias. Em geral, os golpes de Estado são adjudicados à força dos setores golpistas, quando na realidade representam seu fracasso para lutar na arena democrática. Contrastando visivelmente com o sucesso alcançado por partidos de raízes populares, as forças conservadoras ou de direita possuíam uma debilidade congênita no Brasil e, sobretudo, na Argentina, sem conseguir, apesar dos esforços, se firmarem como opção para aceder, exceto em circunstâncias extraordinárias, por meios democráticos à máxima instância de poder (Linz, 1978). Além disso, tinham pouca penetração nos movimentos sociais e inclusive, no caso argentino, várias das organizações industriais e agropecuárias se encontravam divididas em frações com posições escassamente conciliáveis que as levavam a enfrentamentos internos e a diluir seu potencial de pressão.

De todos os modos, isto não era apenas um sintoma local, sem minimizar a raiz interna, também é necessário remarcar que os partidos atravessaram, a partir dos anos 1960 uma crise no mundo todo, como 
salientam o trabalhos clássicos de Otto Kirchkeimer (1980) e Clauss Offe (1990). Muitos foram perdendo algumas de suas facções características, que se apagavam, especialmente à medida que se aproximavam do poder, e, sobretudo, a capacidade para pensar e processar políticas públicas mais amplas, procedendo-se a um distanciamento entre políticos e técnicos profissionais. Os primeiros mais preparados e quase apenas preocupados em ganhar eleições e os segundos tornando-se imprescindíveis para governar, mas bastante inábeis para pleitear o acesso ao poder por meios próprios.

Esses poderiam ser alguns dos motivos para que uma das ações mais visíveis no golpe de 1964 no Brasil fosse a de dois institutos paridos desde o setor empresarial, mas com forte presença militar e tecnocrática, como o Instituto Brasileiro de Ação Democrática (IBAD) e o IPÊS, assim como para que a maior parte da política econômica argentina, durante quase todas as administrações ditatoriais, fosse conduzida por homens ligados à Fundación de Investigaciones Económicas Latinoamericanas (FIEL).

Por intermédio desse tipo de entidades, o empresariado canalizou uma expressiva maneira de agir antes dos golpes. Suas corporações não tinham sintonia com os governos de caráter popular, instalados democraticamente, existindo agudos conflitos, como o mencionado para Argentina entre a UIA e a CGE, e para o Brasil com o governo Goulart, com movimentos que ameaçavam a ordem no campo, nas fábricas e até nas fileiras das Forças Armadas, o que aguçava o enfrentamento, estreitando ainda mais a aliança com atores que se posicionavam nos extremos do espectro político, afastando assim os setores mais moderados e alimentando uma espiral de tensões crescentes.

O IBAD, criado em 1959, concentrou seus esforços para desestabilizar o governo Goulart até 1963, quando suas ligações com os Estados Unidos foram alegadas para ilegalizá-o após um inquérito no Congresso Nacional, momento a partir do qual o IPÊS assumiu esse papel, ocultando tais relações habilmente. Esse último Instituto tinha sido fundado no final de 1961 e, tal como seu nome indica, inicialmente possuía um perfil mais técnico, elaborando propostas para a oposição e atuando na coordenação ideológica contrária aos sectores de esquerda, particularmente através da divulgação de variados tipos de propaganda a favor do sistema capitalista e outras diretamente anticomunistas, nas quais participaram um vasto grupo de empresários, tecnocratas, militares e um punhado de indivíduos ligados à Igreja católica, solidamente organizados, muitos dos quais ocupariam postos chave durante o regime ditatorial. 
A FIEL tinha sido fundada em 1964, atuando como instrumento ideológico da alta burguesia argentina, ao estar nela representadas todas as organizações de cúpula do empresariado, e a sua voz era ouvida amplamente em diversos círculos. Embora tivesse pouca presença militar nos seus quadros e não se ocupasse da ação política direta, conseguiu impor seu discurso e ficar com os principais cargos da área econômica durante esse período e, inclusive, já bem entrado o processo de democratização.

No caso brasileiro as duas instituições mencionadas, e vários de seus membros, se envolveram até mesmo na ação repressiva. De fato, o Sistema Nacional de Informações (SNI), encarregado da inteligência interna do regime, foi engendrado no seio do IPÊS, tendo no general Golbery do Couto e Silva seu mentor; igualmente é opinião corrente que Antônio Delfim Netto, ministro da Fazenda, coletava dinheiro no ambiente empresarial para a Operação Bandeirantes (OBAN). Até mesmo alguns empresários chegariam a se envolver em ações repressivas diretas, como o dinamarquês naturalizado brasileiro Hennig Albert Boilesen, que teve um instrumento de tortura batizado com seu sobrenome como forma de homenageá-lo, tendo sido executado por militantes da Vanguarda Popular Revolucionária (VPR) numa emboscada.

$\mathrm{Na}$ Argentina, o empresariado não participou diretamente do terrorismo de Estado, apenas colaborou, especialmente na delação e fez vistas grossas em relação ao que acontecia, mas não devemos interpretar isso como uma negativa, talvez só indique que não chegou a ser necessária sua participação num nível direto.

De todos os modos e apesar da brutalidade, ações desse tipo não eram o objetivo principal dessas instituições, sua ênfase esteve em elaborar muitas das medidas dotadas pelos governos autoritários na esfera econômica, áreas conexas e outras para as quais se expandiram, assim como para levar adiante a maior parte das políticas econômicas do período, realizando uma verdadeira colonização de determinados aparelhos de Estado. Além de serem contra-revoluções preventivas, as ditaduras tiveram caráter fundacional, com o intuito de remover as causas que levavam à contestação da ordem a que almejavam.

Como seria impossível mencionar, no espaço de um artigo, todos os cargos de primeiro e segundo escalão ocupados por personalidades vinculadas a essas instituições durante os governos autoritários, resumimos que, no caso brasileiro, ocuparam os ministérios da Fazenda, do Planejamento, da Indústria e do Comércio, a Casa Civil e a Militar, vários bancos, a começar pelo Central, uma infinidade de órgãos menores 
e empresas estatais, tendo sido ligados ao IPÊS também os dois últimos presidentes; já, no caso argentino, o Ministério da Economia parecia ser cativo dos membros da FIEL, escapando-lhes apenas a administração do general Roberto Levingston, na qual despontaram algumas posições desenvolvimentistas, assim como a presidência do Banco Central foi-lhes ferramenta de singular valor, mas na qual os laços já são menos perceptíveis.

Não devemos ver isso como uma exclusividade do período, pois se observam circunstâncias parecidas posteriormente. A colonização por membros de institutos desse tipo obedece à lógica da formulação de políticas públicas que começava a mudar naqueles anos, quando passaram a ser necessários conjuntos numerosos de indivíduos com qualificações específicas e articulações prévias para atuar no poder. $\mathrm{O}$ calor da hora podia agrupar pessoas, mas isso não às convertia em equipes, e organiza-las durante o andar da carruagem podia provocar situações desastrosas.

Apesar dessas semelhanças, também podemos marcar algumas diferenças, pois, enquanto no Brasil, após certo tempo, se tendeu a transferir o recrutamento da tecnoburocracia às entidades públicas, que foram expurgadas e recompostas, ou privadas, mas com menor dependência do empresariado; no caso argentino, os órgãos estatais prolongaram seu deterioro, sem que as estruturas partidárias ou da sociedade civil pudessem constituir entidades com as quais competir à altura.

Tal situação é visível no fato de que, no caso brasileiro, o IPÊS foi perdendo relevância a partir de 1967 e sua desmobilização ocorreu desde 1971; já no caso argentino, a FIEL e a FM não só continuaram existindo mas também dominaram, junto com o Centro de Estudios Macroeconómicos de la Argentina (CEMA), criado em 1978, a condução da econômica até 2001, escapando-lhes apenas o interregno alfonsinista e a gestão de Erman González, nos inícios do governo menemista, não sem antes encarar alguns custosos mas necessários e bem sucedidos processos de reconversão.

\section{As alianças nas lutas no front político e ideológico}

Essa capacidade para dominar o processo de formulação de políticas públicas por um extenso período ancorou-se tanto em méritos próprios quanto nas dificuldades que outros competidores encontravam para se lhe opor e propor outros tipos de medidas. O conflito aberto pelas ditaduras foi verdadeiramente profundo, a intenção era privar outras forças sociais 
das faculdades de planejar e conduzir as políticas com o cuidado que as novas circunstâncias do momento requeriam. Além de fazê-o dentro das próprias universidades, tanto públicas quanto privadas, e em outros órgãos estatais dedicados à investigação ou assuntos técnicos, também foram combatidos outros centros de natureza privada, seja por meios indiretos, negando-lhes recursos, por exemplo, ou através da repressão direta. Intelectuais que representavam um perigo potencial foram aposentados compulsivamente, expulsos ou obrigados a marchar ao ostracismo no exterior ou no interior, no melhor dos casos. A tortura e a morte, ou a desaparição, como seu eufemismo, foram expedientes para tratar muitos idealistas recalcitrantes. Procedimentos mediante os quais se desarticulou um rico tecido social.

No Brasil, a sanha repressiva foi dirigida especialmente contra o Instituto Superior de Estudos Brasileiros (ISEB) que, nos seus anos dourados, chegou a receber recursos da Federação das Indústrias do Estado de São Paulo (FIESP). Na Argentina, o Instituto Di Tella foi um dos seus alvos, lembrado por sua atuação no campo das artes, mas atuando também na economia e noutras ciências sociais, sucumbiria em 1969, momento no qual SIAM Di Tella, grupo que era o seu principal financiador e, na época, o maior do país, começou a cambalear. Durante a ditadura instalada em 1976 tal acosso alcançaria o Instituto de Estudios Económicos y Financieros (IEEF), da CGE, que foram saqueados, acabando-se assim com duas das insígnias vinculadas ao modelo substitutivo. Posteriormente, o primeiro instituto argentino se converteria numa universidade privada, perdendo seu pé na economia real, e o segundo seria relançado sem seus antigos brilhos depois da redemocratização, quando sua instituição mãe recuperara a legalidade, mas não seu poder.

Por isso, se estranhou que a condução das finanças públicas durante os primeiros momentos da recuperação democrática procurasse reverter essas tendências, mas as tentativas se prostraram diante do voluntarismo ou do escasso apoio que ideias desenvolvimentistas despertavam no mundo empresarial e nos organismos internacionais, colonizados por posições contrárias. Por isso, os governos necessitaram deixar novamente o comando da economia a atores que tinham atuado durante a ditadura, como Domingo Cavallo, por exemplo, os quais, paradoxalmente, tinham sido os culpados pela crise, mas que agora se apresentavam como os únicos acreditados para enfrentá-la.

De todas as formas, não devemos interpretar esse sucesso como unânime. Apesar de que o dissenso estivesse severamente amordaçado, 
a implantação de políticas públicas de caráter recessivo provocou contratempos nos regimes autoritários, já que afetava os estratos mais pobres, gerando descontentamento e instabilidade, e, ao diminuir o poder de compra, o fazia também com os empresários que viviam do mercado interno, que eram os únicos que ainda podiam alçar suas vozes de descontentamento dentro do próprio círculo de poder, afastando-se muitos deles das alianças que tinham deflagrado os golpes e instaurado as ditaduras. Por isso, as alianças construídas em torno dos golpes eram frágeis e tendiam a entrar em processo de ruptura uma vez que fossem alcançados seus objetivos iniciais (Sidicaro, 2004).

Às vezes a luta pelos cargos mais elevados podia desatar escaramuças palacianas, tão logo produzidos os golpes, verbigracia, disputas entre a "linha-dura" e a "Sorbonne", no caso brasileiro, e a que opunha "azuis" e "colorados", no argentino.

Igualmente isso também podia ocorrer no próprio âmbito empresarial. Como relação social, a economia está submetida a lutas, na qual às vezes os próprios setores burgueses se enfrentam, como fica evidente na divisão do IPÊS pouco depois do golpe, em maio de 1964, por causa de enfrentamentos que opunham empresários paulistas e cariocas; um pouco mais adiante, nas reuniões do Comitê Executivo do IPÊS Guanabara que antecedem ao "milagre", mais precisamente entre 1966 e 1967, escutaram-se duras reclamações acerca dos rumos da política econômica, comandada por Antônio Delfim Netto, que esteve ligado à secional de São Paulo; e, em junho de 1978, o "Documento dos oito", um agrupamento informal dos empresários mais poderosos, também levantou sua voz dissonante em relação à condução da economia, embora tenham se reacomodado rapidamente.

$\mathrm{Na}$ Argentina, além do clássico conflito que opunha as frações agrária e industrial, que dominaram os típicos ciclos de stop-go e se estendem até hoje, também ocorreu a rápida ascensão de setores ligados às finanças a par de conflitos intra-industriais fortes, alguns antigos e outros que se aguçaram quando as políticas de corte neoliberal se aprofundaram. Manifestações contrárias são ouvidas a partir de 1980, como as que, em 1980, pronunciou Domingo Cavallo diante de Guillermo Walter Klein (h), vice-ministro de Economia, num discurso da Fundación Mediterránea ou a dos industriais metalúrgicos rosarinos, que se rebelariam de forma mais violenta, com piquetes e arengas inflamadas, nas quais prometiam transformar em farpas tirar a cadeira presidencial (Simonassi, 1998), mas que, apesar da sua grandiloqüência, tiveram menos efeitos que as ações empreendidas por seus pares mediterrâneos, 
que foram acomodados no poder em posição subalterna em 1981 e 1982.

Essas e outras tensões nos ajudam a compreender por que as medidas econômicas desenhadas por tais Institutos não foram aplicadas in bloco. De fato existiram várias gerações de reformas e as elas não obedeceram apenas ao aprendizado dos quadros técnicos, muitas delas tiveram que esperar até que fossem vencidas certas resistências, não só em segmentos políticos e civis, que faziam oposição aos regimes autoritários, mas também em forças que formavam parte deles, em especial outros grupos militares, empresariais e tecnocráticos. Daí a existência de políticas que hoje podemos interpretar como contraditórias, mas que não o eram de acordo com essa lógica.

Muitos militares eram nacionalistas por formação e/ou vocação e se aproximavam do desenvolvimentismo por motivos estratégicos, já que coincidiam na idéia de que promovendo a industrialização de base se reforçava a soberania; por sua parte, sem negar motivos ideológicos fortes, os empresários e tecnocratas tinham interesses materiais mais específicos. Além de cobrar tributos, que podem ser diferenciais, o Estado atribui recursos, compra e vende, muitas vezes a fundo perdido ou abaixo dos preços do mercado, constituindo assim âmbitos privilegiados de acumulação (Castellani, 2009), mecanismos com os quais se podia alentar ou frear o crescimento de muitos grupos econômicos poderosos, em torno dos quais girava uma miríade de outros pequenos e médios empresários.

Por sua parte, o campo dos economistas, em geral, e daqueles que ocupariam os cargos públicos mais importantes, em particular, estava passando por um giro copernicano, com um período de transição no qual as novas tendências tomavam nitidez e as antigas se apagavam lentamente, situação que incidiria decididamente nas políticas a serem implementadas e na própria formação das alianças.

No caso brasileiro, as corporações econômicas tinham seus próprios centros de pesquisa e as instituições educativas, sejam públicas ou privadas, também, motivo pelo qual o recrutamento de técnicos feita por uma entidade como o IPÊS foi de pessoal com seu processo formativo completo, não realizando nenhum, ou muito poucos, esforços para continuar seu aperfeiçoamento, característica que lhe foi fatal em última instância.

Em relação ao caso argentino, a profissão de economista era de implantação recente, tendo sido abertos bacharelados na Universidad de Buenos Aires (UBA), em 1958, e na Universidad Nacional de Córdoba 
(UNC), em 1966, por exemplo. O que obrigou às entidades a recrutar pessoal em etapa formativa, devendo investir pesadamente em sua qualificação, a maioria das vezes concluída no exterior.

Não obstante, temos advertido que os quadros técnicos de FIEL não chegavam aos principais cargos da condução econômica, fundamentalmente os postos de ministro e presidente do Banco Central, que pareciam estar reservados para alguns diretivos da entidade, que tinham trânsito marginal por esse campo. Desse modo, as credenciais mais importantes não pareciam ser as acadêmicas, mas as de origem social, em especial vir de famílias aristocráticas e pertencer a círculos da elite, particularmente ao Consejo Empresario Argentino (CEA). Apenas com o arribo dos mediterrâneos, os técnicos orgânicos ganharam os primeiros planos. Assim, de forma lenta, mas num processo sem volta, a direita liberal tradicional cedia terreno para a direita liberal tecnocrática ${ }^{3}$.

No caso brasileiro, as origens da tecnocracia parecem bastante similares aos do segmento empresarial. Os tecnocratas que se nuclearam no IPÊS provinham ou tinham sido admitidos pelos círculos mais elevados, estabelecendo uma relação mais horizontal com seus quadros diretivos, situação demonstrada pelo fato de que foram convocados sem maiores reparos para os escalões mais elevados da administração estatal durante esse período.

Não obstante, o discurso tecnocrático ainda era dependente, precisando de outros recursos e da ajuda de outros atores para conseguir se impor. Desde essa perspectiva podemos interpretar melhor o uso profuso que os empresários faziam do discurso nacional e católico, assim como a particular atenção em cultivar relações com religiosos, tanto da hierarquia como outros do baixo clero, o que foi fundamental na desestabilização dos regimes democráticos e na legitimação dos governos ditatoriais. No caso brasileiro, as forças golpistas convocaram, com a ajuda da Igreja, gigantescas marchas contra o regime democrático e em apoio ao novo governo; no caso argentino, é emblemático que Cavallo chegasse por primeira vez à política nacional, em 1981, por intermediação de Raúl Francisco Primatesta, cardeal primado de Córdoba. Apenas mais adiante os empresários poderiam prescindir dessa ajuda, a qual passou a ser-lhe esquiva no caso brasileiro quando a cúpula eclesiástica começou a se distanciar, em especial após 1967, momento em que mudou o comando da Confederação Nacional dos Bispos do

3 Categorias empregadas por Guillermo O’Donnell (1997). 
Brasil (CNBB), afastamento que também nos ilustra sobre as mudanças alcançadas pelas próprias alianças golpistas, que chegaram ao final dos regimes autoritários fortemente reconfiguradas.

Tal constatação oferece oportunidade para concluirmos que as ditaduras não foram uniformes nem lineares, estando sua peculiar topografia fortemente influenciada pela dinâmica que lhe imprimiam os atores sociais. Estes não atuavam em bloco, nem isolados, estabeleciam alianças nas quais se os uniam por questões de curto ou longo alcance, algumas que precediam esses eventos e outras que os sobreviveram. É precisamente por atuarem em períodos extensos que as estas alianças estiveram sujeitas a profundas mudanças. Algumas delas obedeciam às transformações sofridas pelos próprios atores, outras às condições políticas que as administrações provocavam. Modificações na natureza de determinados agentes causavam também desequilíbrios, alterando seus pesos na frágil composição e, dependendo do curso dos acontecimentos, antigos aliados podiam se enfrentar enquanto que outros novos podiam se atrair, alterando as feições originais de tais alianças, chave interpretativa que pode nos explicar as sucessivas nuanças que seguiram.

\section{Referencias}

CANELO, Paula. La política contra la economía: los elencos militares frente al plan económico de Martínez de Hoz durante el Proceso de Reorganización Nacional (19761981). In: PUCCIARELLI, Alfredo (Coord.). Empresarios, tecnócratas y militares. La trama corporativa de la última dictadura. Buenos Aires: Siglo XXI, 2004. p. 218-312.

CASTELLANI, Ana. Estado, empresas y empresarios. La construcción de ámbitos privilegiados de acumulación entre 1966 y 1989. Buenos Aires: Prometeo Libros, 2009.

DEZALAY, Ives; GARTH, Bryant G. The internationalization of palace wars. Lawyer, Economists, and the Contest to Transform Latin American States. Chicago/Londres: Universidade de Chicago, 2002.

DREIFUSS, René Armand. 1964: A conquista do Estado. Ação Política, Poder e Golpe de Classe. Petrópolis: Vozes, 1981.

JÁUREGUI, Anibal. Empresarios y politicas de desarrollo en la Argentina y el Brasil 1920-1955. 2002. Tese (Doctorado) - Universidad Nacional del Centro de la Provincia de Buenos Aires, Tandil.

HUNTINGTON, Samuel P. El orden político en las sociedades en Cambio. Buenos Aires: Paidos, 1992.

KIRCHKEIMER, Otto. El camino hacia el partido de todo el mundo. In: LENK, Kurt e NEUMANN, Franz (Ed.). Teoría y sociología crítica de los partidos políticos. Barcelona: Anagrama, 1980, p. 246-328.

LINZ, Juan. Una interpretación de los regímenes autoritarios. Papers - Revista de Sociología de la Universidad Autónoma de Barcelona, Barcelona: Ediciones Península, n. 8, p. 11-27, 1978. 
OFFE, Claus. Contradicciones en el Estado de Bienestar. Madri: Alianza Editorial, 1990 .

MARTINS FILHO, João Roberto. O palácio e a caserna: a dinâmica militar das crises políticas da ditadura, 1964-1969. São Carlos: Edufscar, 1995.

NUN, José; PORTANTIERO, Juan Carlos (Comp.). Ensayos sobre la transición democrática en la Argentina. Buenos Aires: Puntosur, 1987.

O’DONNELL, Guillermo. El Estado Burocrático Autoritario: Triunfos, derrotas e crisis, 1966-1973. Buenos Aires: Editorial de Belgrano, 1982.

O’DONNELL, Guillermo. Estado y alianzas en la Argentina, 1956-1976. Desarrollo Econômico, Buenos Aires: IDES, v. 16, n. 64, p. 523-554, jan./mar. 1977.

O’DONNELL, Guillermo. Las fuerzas armadas y el Estado autoritario del Cono Sur de América Latina. In: Contrapuntos. Ensayos escogidos sobre autoritarismo y democratización. Buenos Aires: Paidós, 1997.

SCHVARZER, Jorge; SIDICARO, Ricardo. Empresarios y Estado en la reconstrucción de la democracia en la Argentina. El Bimestre Politico y Economico, Buenos Aires: CIESEA, n. 35, p. 5-14, 1987.

SCHMITTER, Philippe C. ¿Continúa el siglo del corporativismo? In: SCHMITTER, Philippe C.; LEHMDRUCH, Gerhard (coords.). Corporativismo I. Mas allá del Mercado y del Estado. México: Alianza, 1992. p. 15-66.

SIDICARO, Ricardo. El Régimen Autoritario de 1976: Refundación Frustrada y Contrarrevolución Exitosa. In: TCACH, César e QUIROGA, Hugo. A Veinte Años del Golpe. Con Memoria Democrática. Rosario: Homo Sapiens, 1996. p. 9-26.

SIDICARO, Ricardo. Coaliciones golpistas y dictaduras militares: el "Proceso" en perspectiva comparada. In: PUCCIARELLI, Alfredo (coord.). Empresarios, tecnócratas y militares. La trama corporativa de la última dictadura. Buenos Aires: Siglo XXI, 2004, p. 53-96.

SIKKINK, Kathryn. Las capacidades y la autonomía del Estado en Brasil y la Argentina: un enfoque neoinsitucionalista. Desarrollo Económico, Buenos Aires: IDES, n. 128. p. 543-574, jan./mar. 1993.

SIMONASSI, Silvia. Entre la adhesión activa y el desencanto. Acerca de los industriales metalúrgicos del gran Rosario y el "Proceso". Avances del CESOR. Rosário: Universidad Nacional de Rosário, p. 95-107, 2do. semestre de 1998. 